\title{
Comparative study of user friendliness of paperless partogram compared to WHO partogram in preventing prolonged labour
}

\author{
Faswila M.*, Smitha B. Rao
}

Department of Obstetrics and Gynecology, Yenepoya Medical College, Mangalore, Karnataka, India

Received: 24 October 2018

Accepted: 28 November 2018

\section{*Correspondence:}

Dr. Faswila M.,

E-mail: m_faswila@yahoo.com

Copyright: (C) the author(s), publisher and licensee Medip Academy. This is an open-access article distributed under the terms of the Creative Commons Attribution Non-Commercial License, which permits unrestricted non-commercial use, distribution, and reproduction in any medium, provided the original work is properly cited.

\begin{abstract}
Background: Partogram is being used since 1954 when Friedman described it for monitoring progress of labour. The Paperless Partogram proposed by Dr. Debdas is a low-skill method for detection of abnormal labour. The objective of the present study was to know efficacy and user friendliness of paperless partogram in comparison with WHO partogram in monitoring and management of labour

Methods: It's a comparative study. Total of 100 patients were included in the study where half of the patients were monitored by paperless partogram and the other half by WHO modified partogram. The plotting of the WHO partographs started as soon the cervical dilatation was $4 \mathrm{~cm}$ along with regular painful uterine contractions. In the paperless partogram calculation will be two times, an ALERT ETD (estimated time of delivery) and an ACTION ETD. The outcome of labour will be recorded at the end of each partographs.

Results: Paperless partogram was better than WHO partogram in terms of documentation, ease of use, learning, time factor, cost effectiveness and monitoring of labour, identification of abnormal labour.

Conclusions: In present study paperless partogram was found to be preferred for monitoring of labour.
\end{abstract}

Keywords: Labour monitoring, Modified WHO partogram, Paperless partogram

\section{INTRODUCTION}

About 830 women die around the world every day due to pregnancy or child birth which accounts for maternal mortality. In 2015 it is estimated that roughly 303000 women died during and following pregnancy and childbirth. Between 2016 and 2030, as part of the Sustainable Development Goals, the target is to reduce the global maternal mortality ratio to less than 70 per 100 000 live births. India has a high maternal mortality of about 540 per $1,00,000$ births of which $10 \%$ is due to obstructed labour. ${ }^{1}$

The first obstetrician to describe the progress of labour graphically was Friedman following his study of the cervical dilatation of 100 African primigravidae at term. ${ }^{2}$ The women were given frequent vaginal examinations and their progress was recorded in centimetres of dilatation per hour, producing a slope resembling a sigmoid curve (' $\mathrm{S}$ ' shaped). This became known as the cervicograph. In an attempt to utilise midwives efficiently in a hospital and clinic service in Zimbabwe (then Rhodesia), where doctors were in short supply developed a partogram from this original cervicograph. ${ }^{3}$ This provided a practical tool for recording all intrapartum details, not just cervical dilatation. An 'alert line' was added following the results of a prospective study of 624 women. ${ }^{4}$ The alert line was straight not curved and was a modification of the mean rate of cervical dilatation of the slowest $10 \%$ of primigravida women who were in the active phase of labour. This line represented a progress rate of $1 \mathrm{~cm}$ per hour. Should a woman's cervical dilatation progress more slowly, it would cross this alert line and arrangements were made to transfer her from a 
peripheral unit to a central unit where prolonged labour could be managed. The next stage of partogram development was the introduction of an 'action line', four hours to the right of the alert line. ${ }^{5}$

This line was developed to identify primary inefficient uterine activity to prompt appropriate management. Correction of primary inefficient uterine activity would usually be with an intervention such as amniotomy or oxytocin infusion, or both.

There have been a number of challenges associated with partograph completion, including shortages of human resources, low status within labour wards and inadequate training. ${ }^{6,7}$ These challenges have resulted in a number of adaptations to the original partograph, one of which is the simplified partograph. ${ }^{8}$

It's a graphical representation of the various events of labour plotted against time which depicts the progress of labour at a glance.

It's very cost effective and affordable health intervention for monitoring labour and appropriate decision making." The earlier WHO partographs was the Composite partographs which was modified in 2000 by eliminating the latent phase to form WHO modified partographs. ${ }^{9}$ WHO recommends Modified Partogram for labour monitoring, but it is rarely used and when used is incorrectly interpreted.

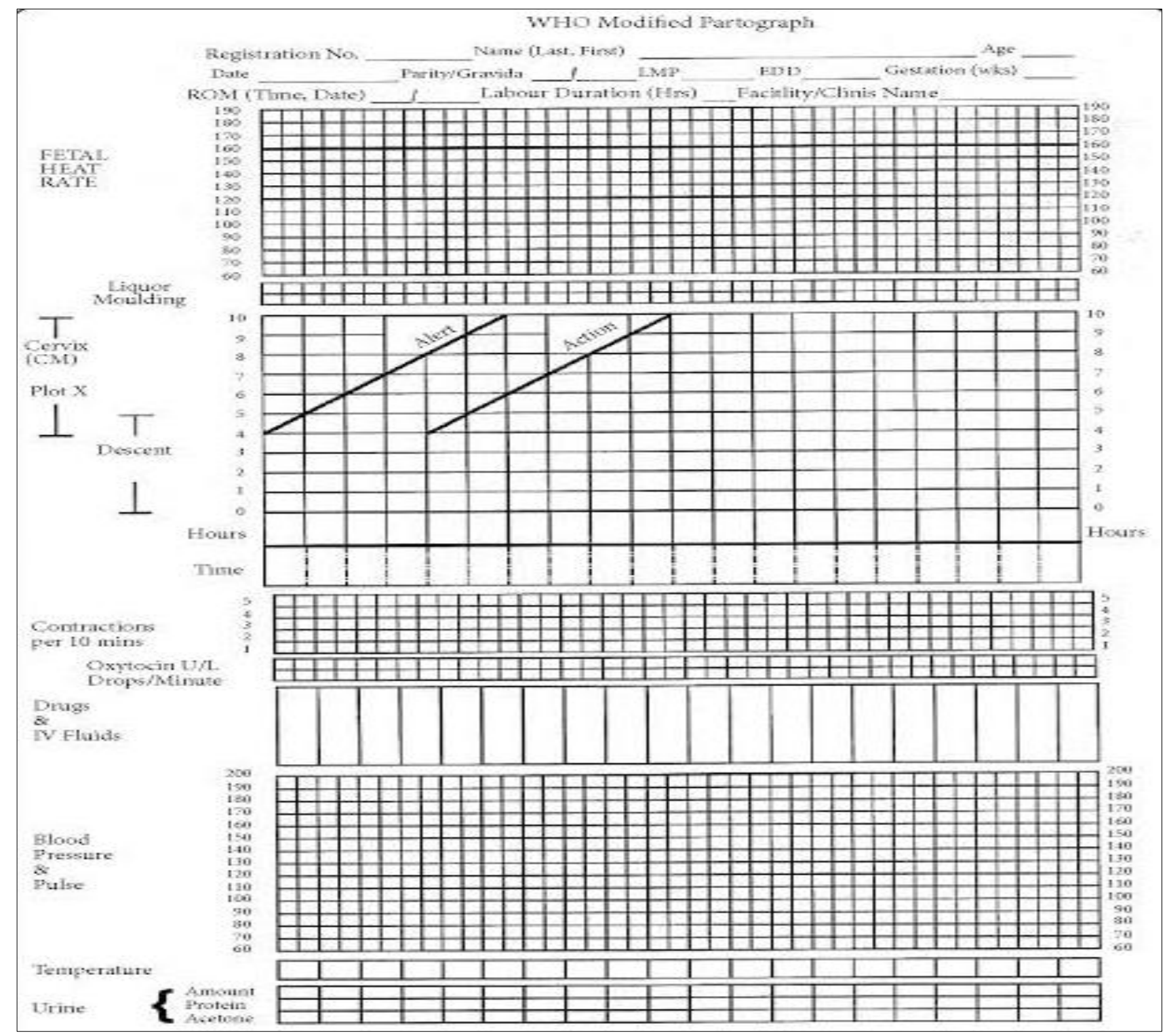

Figure 1: WHO modified partograph. 
Paperless Partogram was proposed by Dr. Debdas, lowskill method for detection of abnormal labour. It serves as an early warning system and assists in early decisionmaking regarding transfer, augmentation and termination of labour. It uses a simple, non-time consuming, two step calculation requiring only basic addition and the reading of a clock/ watch. It identifies slow progress of labour, the time to intervene and terminate labour or to transfer a woman to higher centres with facilities for Caesarean section. ${ }^{10}$ The present study is proposed to evaluate the effectiveness of Paperless Partogram in comparison with WHO modified partogram in the management of labour.

\section{METHODS}

The study was carried out in Yenepoya Medical College Hospital, Department of Obstetrics and Gynaecology, from June to July 2018. It is a hospital based prospective analytical study. During the period of present study the course of labour in 100 women was studied.

\section{Inclusion criteria}

- Both Primigravida and Multigravida with

- Singleton

- Term (37-41 weeks) pregnancies

- Vertex presentation

- Patient who went into spontaneous and induced labour.

\section{Exclusion criteria}

- Patients with any complications attending the labour room for delivery

- Multigravida more than 3 parity

- Previous scarred uterus.

Demographic details and history of all patients were taken and those willing to participate after an informed and written consent were included in the study. Half of the patients (50) were monitored by paperless partogram in group A and the other half group B were monitored by WHO modified partogram. The plotting of the WHO partographs was started as soon the cervical dilatation was $4 \mathrm{~cm}$ along with regular painful uterine contractions. In the paperless partogram, an ALERT ETD (estimated time of delivery) and an ACTION ETD is noted. The estimated time of delivery ( 6 hours after $4 \mathrm{~cm}$ of cervical dilation) considered the "Alert ETD" to which 4 hours were added to obtain the "Action ETD". At the time of the Action ETD, if woman had not yet delivered, a diagnosis of abnormal or prolonged labor was made and patient was delivered by caesarean section.

\section{RESULTS}

Out of 100 women who participated in the study 55 $(55 \%)$ were primipara and $45(45 \%)$ were multipara. The mean age of the participants was 26.36 years and the mean duration of gestation was 38 weeks \pm 1 weeks. The mean weight of the new born child was $2.9 \mathrm{~kg}$ (Table 1).

Table 1: Baseline information of the participants.

\begin{tabular}{|lll|}
\hline Variables & Range & Mean \\
\hline Age & $20-32$ years & 26.36 years \\
\hline Gestational age & $36-41$ weeks & 38.4 weeks \\
\hline Weight of new born & $2.5-4 \mathrm{~kg}$ & $2.9 \mathrm{~kg}$ \\
\hline
\end{tabular}

Out of 55 primigravida, spontaneous delivery took place in $50(91 \%)$ participants and in $5(9 \%)$ cases, delivery was induced. Out of 45 multipara, $34(76 \%)$ delivered spontaneously and in 11 (24\%) cases were induced.

Out of 100 participants 5 (9.1) primigravida delivered by lower segment Cesarean section (LSCS) 1 (2\%) multi gravid delivered by lower segment caesarean section (Table 2).

Table 2: Mode of delivery.

\begin{tabular}{|lllll|}
$\begin{array}{l}\text { Mode of } \\
\text { delivery }\end{array}$ & $\begin{array}{l}\text { Primipara } \\
\text { n }\end{array}$ & $\%$ & $\begin{array}{l}\text { Multipara } \\
\text { n }\end{array}$ & $\%$ \\
\hline Vaginal & 50 & 90.9 & 44 & 97.78 \\
\hline Caesarean & 5 & 9.1 & 1 & 2.22 \\
\hline Sponatneous & 50 & 90.9 & 34 & 75.55 \\
\hline Induced & 5 & 9.1 & 11 & 24.4 \\
\hline
\end{tabular}

Further on following up for mode of delivery 42(85\%) of cases monitored by the Paperless partograph and $38(76 \%)$ cases monitored by WHO partograph had a spontaneous delivery. Caesarean section was required in $13 \%$ cases monitored by Paperless partograph as against $18 \%$ cases of WHO partograph (Table 3 ).

Table 3: Follow up of mode of delivery.

\begin{tabular}{|lllll|}
\hline Mode of delivery & \multicolumn{2}{c}{ Group a } & \multicolumn{2}{c|}{ Group b } \\
\hline Vaginal & N & \% & N & \% \\
\hline Cesarean section & 44 & 87 & 41 & 82 \\
\hline Spontaneous & 6 & 13 & 9 & 18 \\
\hline Assisted & 42 & 85 & 38 & 76 \\
\hline
\end{tabular}

$2(4 \%)$ in Paperless group and 3(6\%) in WHO group required assisted delivery. Thus, course of labour with Paperless partograph was comparable with that of WHO modified partograph. Table 4 depicts the time taken for delivery in both primigravidae and multigravida after Alert ETD. There were 18 cases in primigravidae and 28 multigravida who took 6-7 hours, 16 and 10 primigravida and multigravida respectively who took 8-9 hours, there were 18 primigravida and 7 multigravida who took 10-11 hours for delivery., but there were 3 cases amongst primigravidae who crossed 12 hours and above but no multigravida .Hence overall mean duration was found to be $4.7 \pm 1.9$ hours in primigravida and $3.7 \pm 1.8$ hours in 
multipara, but these differences were not statistically significant.

Table 4: Time taken after ALERT ETD (Hrs) in study participants.

\begin{tabular}{|l|l|l|}
\hline Duration & Primi & Multi \\
\hline 6-7 hours & 18 & 28 \\
\hline 8-9 hours & 16 & 10 \\
\hline 10-11 hours & 18 & 7 \\
\hline Above 12 hours & 3 & 0 \\
\hline Overall duration (range) hours & $4.7 \pm 1.9$ & $3.7 \pm 1.8$ \\
\hline
\end{tabular}

Table 5 depicts the case distribution in relation to alert and action line estimated time delivery. In group A, there were 42 cases $(84 \%)$ who delivered within alert line or alert estimated time of delivery whereas in group B there were $37(74 \%)$ patients who delivered within alert line or alert estimated time of delivery. There were $7(14 \%)$ cases in group A and 9(18\%) cases in group B who delivered between alert and action line. There was only 1 case $(2 \%)$ in group A and 4 cases (8\%) in group B who delivered beyond the action time.

Table 5: Table showing distribution of cases in relation to alert and action line ETD.

\begin{tabular}{|lllll|}
\hline Variable & Group a & \multicolumn{3}{c|}{ Group b } \\
\hline $\begin{array}{l}\text { Within alert line/ } \\
\text { alert ETD }\end{array}$ & 42 & 84 & 37 & 74 \\
\hline $\begin{array}{l}\text { Between alert } \\
\text { and action ETD }\end{array}$ & 7 & 14 & 9 & 18 \\
\hline $\begin{array}{l}\text { Beyond action } \\
\text { line ETD }\end{array}$ & 1 & 2 & 4 & 8 \\
\hline Total & 50 & 100 & 50 & 100 \\
\hline
\end{tabular}

Table 6 depicts the complications which occurred during labour the main complication encountered was prolonged labour and postpartum haemorrhage. In group A 11 cases (22\%) had prolonged labour, whereas in group B only 5 cases $(10 \%)$ had prolonged labour. In group A there were 2 cases of post-partum haemorrhage whereas in group B there were no cases reported who had post-partum haemorrhage.

Table 6: Complications occurring during labour.

\begin{tabular}{|c|c|c|c|c|c|}
\hline \multirow{2}{*}{$\begin{array}{l}\text { Complication: } \\
\text { during labour }\end{array}$} & \multirow{2}{*}{$\begin{array}{l}\text { Total } \\
\text { number } \\
\text { (n) }\end{array}$} & \multicolumn{2}{|c|}{ Group A } & \multicolumn{2}{|c|}{ Group B } \\
\hline & & $\mathbf{N}$ & $\%$ & $\mathbf{N}$ & $\%$ \\
\hline $\begin{array}{l}\text { Prolonged } \\
\text { labour }\end{array}$ & 16 & 11 & 22 & 5 & 10 \\
\hline $\begin{array}{l}\text { Postpartum } \\
\text { haemorrhage }\end{array}$ & 2 & 2 & 4 & 0 & 0 \\
\hline
\end{tabular}

Table 7 depicts the indication for caesarean section in both primigravida and multigravida out of 7 LSCS in total.
Table 7: Indications for caesarean section.

\begin{tabular}{|lllll|}
\hline Indication for & \multicolumn{2}{c}{ Primigravida } & \multicolumn{2}{c|}{ Multigravida } \\
\hline ceaseraen section & $\mathbf{N}$ & $\mathbf{\%}$ & $\mathbf{N}$ & $\mathbf{\%}$ \\
\hline Arrest disorders & 3 & 43 & 1 & 14 \\
\hline Protraction disorders & 2 & 29 & 0 & 0 \\
\hline Fetal distress & 1 & 14 & 0 & 0 \\
\hline
\end{tabular}

$3(43 \%)$ were done for arrest disorder and 2 (29\%) were for protraction disorder and $1(14 \%)$ for fetal distress and in multigravida only $1(14 \%)$ case were observed for arrest disorder. One can observe that paperless partographs and modified WHO partogram were equally efficacious in monitoring labour but paperless partogram was less time consuming, easier to train others (interns, nurses) on the utility and maintenance of paperless partographs.

\section{DISCUSSION}

The partogram is a tool that enables midwives and obstetricians to record maternal and fetal observations simply and pictorially. Different designs of the partogram exist and Cartmill and Thornton hypothesized that the way a partogram is presented may affect a midwife's or obstetrician's perception of the labor progress, and thus, influence the decision-making. ${ }^{11}$ This hypothesis has received some support from others, Lavender et al Tay and Yong. ${ }^{12,13}$

Although the WHO recommends universal application of the partogram, the evidence for supporting this recommendation is limited. ${ }^{14}$ Even though WHO modified the partograph model to make it more userfriendly in 2000, the partograph is still rarely used in low health care areas but not many authors assessed the effectiveness of paperless partogram in the management of labour. ${ }^{4}$

Fatou et al. from Egypt studied 100 women and variables like mode of delivery, birth outcome, birth weight, Apgar score and other any complications were noted. ${ }^{15}$ Mean Apgar score after 5 minutes was found to be 9.4. There was no complication of labour. Mean duration for delivery after Alert ETD was 3.5 \pm 2.1 hours in primigravida and $3.3 \pm 2.1$ hours in multipara. It was concluded that the paperless partogram was effective in the management of labour. The main advantage was- care giver need not plot many other parameters in the chart to monitor labour. Study from India, Agarwal et al included 91 women, of which $13 \%$ was induced labor. ${ }^{16}$

They monitored women in labour on the basis of Alert estimated time of delivery (ETD) and Action ETD. At the time of the Action ETD, if delivery had not yet occurred, a diagnosis of prolonged labour was made and arrangements were made for emergency caesarean section. 
The mean duration for delivery after Alert ETD was 4.3 hours that was similar to the World Health Organization's (WHO) recommendation for partograms, with a fourhour action line. Partograph is too time-consuming for overburdened clinicians and too complicated for many skilled birth attendants: many of whom have not received higher education.

The paperless partogram proposed by Dr. Debdas, lowskill method for preventing abnormal labor. In present study, which used the paperless partogram for the management of labor, out of 50 participants, labor was prolonged only in $11(22 \%)$ cases, which is lower than in a study of an uncomplicated primigravida population, which used the WHO partogram, in which $51.3 \%$ of women were diagnosed as being in 'prolonged' labor (ranging from $57.3 \%$ in the two-hour arm to $45.3 \%$ in the four-hour arm). ${ }^{12}$ The mean duration for delivery after Alert ETD was $4.7 \pm 1.9$ hours in primigravida and $3.7 \pm 1.8$ hours in multipara, however, these differences were not statistically significant. The Cesarean delivery rate was $7 \%$ in present study. The mean duration for delivery after Alert ETD was 4.3 hours in both primigravidae and multigravida in present study, which was similar to the WHO recommendation for partograms with a four-hour action line instead of a two-hour action line, denoting the timing of intervention for prolonged labor.

\section{CONCLUSION}

In summary, the paperless partogram was found convenient and effective in the management of labor. The paperless partogram was found to be an effective handover tool, ensuring that the women continued to be monitored for prolonged labor. The paperless partogram illustrates the potential for about 20 seconds and two-time stamps, to help save the lives of mothers and babies. This method can be implemented at the Primary Health Centers/Community Health Centers (PHC/CHC), as they will help in reducing maternal mortality, without any additional cost.

Funding: No funding sources

Conflict of interest: None declared

Ethical approval: Not required

\section{REFERENCES}

1. Maternal mortality. World Health Organization. Available from: http://www.who.int/news-room/factsheets/detail/maternal-mortality

2. Friedman E. The graphic analysis of labor. Am J Obstet Gynecol. 1954;68(6):1568-75.

3. Philpott RH. Graphic records in labour. Br Med J. 1972;4(5833):163-5.

4. Philpott RH, Castle WM. Cervicographs in the management of labour in primigravidae. I. The alert line for detecting abnormal labour. J Obstet Gynaecol Br Commonw. 1972;79(7):592-8.

5. Philpott RH, Castle WM. Cervicographs in the management of labour in primigravidae. II. The action line and treatment of abnormal labour. J Obstet Gynaecol Br Commonw. 1972;79(7):599602.

6. Fatusi AO, Makinde ON, Adeyemi AB, Orji EO, Onwudiegwu U. Evaluation of health workers' training in use of the partogram. Int $\mathrm{J}$ Gynaecol Obstet Off Organ Int Fed Gynaecol Obstet. 2008;100(1):41-4.

7. Lavender T, Hart A, Smyth RM. Effect of partogram use on outcomes for women in spontaneous labour at term. Cochrane Database Syst Rev. 2012;8:CD005461.

8. Mathews JE, Rajaratnam A, George A, Mathai M. Comparison of two World Health Organization partographs. Int J Gynaecol Obstet Off Organ Int Fed Gynaecol Obstet. 2007;96(2):147-50.

9. World Health Organization, International Confederation of Midwives, editors. Education material for teachers of midwifery: midwifery education modules. 2nd ed. Geneva [Switzerland]: World Health Organization: International Confederation of Midwives; 2008.

10. Ogwang S, Karyabakabo Z, Rutebemberwa E. Assessment of partogram use during labour in Rujumbura Health Sub District, Rukungiri District, Uganda. Afr Health Sci. 2009;9(1):S27.

11. Cartmill RSV, Thornton JG. Effect of presentation of partogram information on obstetric decision-making. Int J Gynecol Obstet. 1993;40(2):1520-2.

12. Lavender T, Alfirevic Z, Walkinshaw S. Partogram action line study: a randomised trial. Br J Obstet Gynaecol. 1998;105(9):976-80.

13. Tay S-K, Yong T-T. Visual Effect of Partogram Designs on the Management and Outcome of Labour. Aust N Z J Obstet Gynaecol. 1996;36(4):395-400.

14. World Health Organization partograph in management of labour. World Health Organization Maternal Health and Safe Motherhood Programme. Lancet Lond Engl. 1994;343(8910):1399-404.

15. Fatouh E, Ramadan S. Effect of Using Paperless Partogram on the Management and Outcome of Labour and the Nurses' Opinion. J Educ Pract. 2015;6(8):17-23.

16. Agarwal K, Agarwal L, Agrawal VK, Agarwal A, Sharma M. Evaluation of paperless partogram as a bedside tool in the management of labor. J Fam Med Prim Care. 2013;2(1):47-9.

Cite this article as: Faswila M, Rao SB.

Comparative study of user friendliness of paperless partogram compared to WHO partogram in preventing prolonged labour. Int J Reprod Contracept Obstet Gynecol 2019;8:229-33. 